\title{
REGRAS PARA O DESENVOLVIMENTO ECONÔMICO: Constitucionalismo no Direito Econômico Internacional.
}

RULES FOR ECONOMIC DEVELOPMENT. Constitucionalism in International Economic Law

\section{('arlos Mauricio Sakata Mirandola.}

\begin{abstract}
Resumo:
Esta matéria é destinada às regras para desenvolvimento econômico internacional, embasado no constitucionalismo do Direito Econômico Intermacional, e voltada às propriedades privadas, sociedades civis, tendo como parâmetro, as garantias constitucionais.
\end{abstract}

Palavras-chave: ('onstituição econômica internacional. Legitimidade da deliberação pulítica internacional. Garantias constitucionais.

\begin{abstract}
:
This article refers to the rules for the international economic development, based in the constitutionalism of the International Economic Law. and directed to private properties, civil societies, having as parameter, the constitutional guarantees.
\end{abstract}

Keywords: International economic constitution. Legitimacy of the intmational politcs deliberation. Constitutional guarantees.

\section{Introdução}

Pode o conjunto de normas referentes à regulação das transações ecunômicas internacionais ser referido como uma Constituição Econômicu Intcrnacional? Para um conjunto de autores a serem referidos infra.' a incorporação de uma linguagem constitucionalista ao direito das relações econômicas internacionais é plenamente factível e acertada. No entanto, o tema é controverso e é necessária uma construção doutrinária que seja consistente com a história institucional do sistema $\mathrm{OMC}$, que dê conta da complexidade e da natureza das normas jurídicas nele inscritos e, ao mesmo tempo. consiga certa correspondência com alyuma das doutrinas constitucionais vigentes. A discussão envolve o problema de como tratar das questões de democracia, da cooperação e do direito, num mundo em que as relações politicas e econômicas transburdam os limites das comunidades políticas nacionais.

Mestre e Doutorando em Direito Internacional pela Faculdade de Direito da Universidade de São Paulo.

Tal debate, muito vivo na alualidade, tomou furça após a celebração dos Acordos de Marrakesh e marca a incorporação de uma noı dimensão an direito das relaçōes internacionais - a dimensão da legitimidade. Vide infra. 
A hipótese com que se trabalha neste texto é a de que, se uma Constituição for vista como conjunto de regras que funda uma comunidade política, as regras advindas do processo histórico de evolução do GATT que culminou nos acordos de Marrakesh e conseqüente criação da OMC podem ser consideradas constitucionais. Neste sentido, a idéia de uma Constituição Econômica Internacional, nascida dos acordos já assinados e ainda em negociação no âmbito da $\mathrm{OMC}$, mais do que uma criação para içar as bases ideológicas para um movimento constitucionalista de amplitude internacional, tem como principal preocupação a criação do arcabouço juridico que legitime a asserção de que uma comunidade econômica internacional seria possivel. ${ }^{2}$

O argumento que se segue está organizado do seguinte modo. Na parte (2), situar-se-á a discussão doutrinária sobre a noção de Constituição Econômica Internacional. Na parte (3), far-se-á uma avaliação sucinta e crítica de tais doutrinas, apontando, de modo genérico suas insuficiências. Nas partes (4), e (5) tentam recuperar o sentido original da constitucionalização, elemento faltante nas doutrinas expostas. Tal elemento é aquele da legitimidade. Sendo assim, a definição que scrá adotada de Constituição é "um corpo consistente de regras que fundam a cooperação democrática entre os membros de uma comunidade definida" As partes (6), (7), (8) e (9) fazem a análise da aplicabilidade da definição apresentada às relações econômicas internacionais. Deste modo, verificar-se-á a compatibilidade do direito da OMC com uma doutrina constitucional. Será discutido, sucintamente, por que o regime do GATT 1947 não deu origem a uma Constituição Econômica Internacional - enquanto, sob a égide da OMC, ela pôde surgir. Em (10), (11), (12), (13) e (14), a dimensão da realidade será incorporada. Em outras palavras, far-se-á uma breve discussão sobre como as nações buscam aumentar o bem-estar de suas comunidades nacionais, através da integração internacional e como devem ser interpretadas, por isso, as regras de comércio internacional. Frisar-se-á alguns processos que caracterizam as relações produtivas internacionais, entre eles a transacionalização das economias, criação de uma esfera de interesses globais e pela incorporação da necessidade de legitimação das normas através do respeito à autonomia das deliberações sobre o bem-estar das comunidade domésticas.

\footnotetext{
$\mathrm{Na}$ atualidade, mais do que regras mínimas que regulam as relações entre os Lstados de modo a proscrever condutas soberanas que impliquem a redução do bem-estar de outros Estados, as normas de comércio internacional têm uma característica multilateral e visam a possibilitar a integração econômica. Considerando-se que o movimento de integrar economias não se dá por decreto mas. sim por microdecisões quotidianas, tomadas pelos cidadãos na sua individualidade, identifica-se a criação de uma Comunidade Econômica Intemacional. Perante ela, os Estados representantes da vontade popular nos fóruns de negociação internacional - comprometem-se a não-somente se abster de implementar políticas públicas domésticas que lesem o benı-estar das comunidades politicas nacionais mas. também, a cooperar de forma a aumentar o bem-estar de toda a Comunidade Econômica Intenacional.
} 
Será dada especial ênfase no papel dos paises em desenvolvimento, para a definição da natureza do atual pacto que une os povos. Explicitar-se-á as implicações das regras multilaterais de comércio para o ambiente econômico internacional, mostrando como regras podem criar um meio propício para o aumento de bem-estar social. Além disso, será ressaltada a diferença entre liberalização comercial e integração, assumindo um critério welferista. Daí será derivada a natureza do compromisso entre os países, tendo em vista a heterogenia dos membros da comunidade internacional. Isso permitirá uma discussão sobre a maneira pela qual a integração econômica internacional permite uma melhoria no bem-estar das nações.

\section{As doutrinas constitucionalistas}

O uso da expressão "constitucionalização" das Relações Econômicas Internacionais não é pacífico na doutrina, variando de acordo com os objetivos dos autores. $^{3}$ A referência que dá início à doutrina que incorpora a linguagem constitucionalista ao direito do comércio internacional encontra-se em Jackson (1969), num capítulo - o último, de fato - intitulado "The Constitutional Structure of a Possible International Trade Institution" Nele, o autor defende a criação de instituições para o manejo das relações econômicas internacionais. Seu argumento segue na linha de que elas teriam a função de permitir que governos nacionais implementassem objetivos políticos legítimos ao mesmo tempo em que evitariam que tais objetivos fossem utilizados para perseguir interesses particulares às expensas de um bem-estar comum maior. Além disso, tais instituições se voltariam a permitir que a "sociedade de pessoas ou nações" (society of persons or nations) se organizasse, de modo a permitir que seus membros perseguissem metas comuns, sem serem frustrados por condutas "antisociais" (na terminologia aqui utilizada, não-cooperativas) de outros membros do grupo. No final das contas, o que importaria seriam os procedimentos, ao invés de uma ou outra regra de conduta comercial (Jackson, 1969: 788). Deste modo exposta, esta doutrina primava por fazer uma defesa de regras para o comércio internacional - conflitos internacionais deveria ser solucionados não pela força (power-oriented approach) mas, sim, pelo recurso a regras (rules-oriented approach).

Deste conjunto de insights nascem diversas doutrinas. Tendo em vista algumas características comuns observadas entre as diferentes concepções de constituição, oferece-se aqui uma classificação para efeitos meramente didáticos de

3 Não se discutirá criticamente as doutrinas constitucionalistas. Para uma análise detalhada, com classificações e discutindo a evolução da utilização da linguagem constitucionalista nas relações econômicas internacionais, vide Mirandola (2003). 
expô-las, reconstruindo seus principais argumentos e discutindo-as criticamente. Serão três os tipos ideais que serão apresentados:

1. As doutrinas lihertárias caracterizar-se-ão pela ênfase dada em cinco aspectos. Em primeiro lugar, terão uma forte tendência evolucionista, no sentido de encarar a incorporação de elementos do constitucionalismo ao Direito Econômico Internacional como uma necessidade e um avanço. Em segundo. as justificações para tal relacionar-se-ão principalmente com a necessidade de se instituir sistemas de freios e contrapesos institucionais para que desequilíbrios políticos inerentes às comunidades políticas atuais sejam corrigidos. Em terceiro lugar, há latente nestas doutrinas uma preocupação com a interferência dos governos nacionais estrangeiros ou domésticos - no bem-estar dos indivíduos. Em quarto lugar, como corolário do elemento anterior, transparece uma preocupação de dotar os agentes privados de instrumentos juridicos que garantam suas liberdades econômicas, geralmente sob uma justificação de natureza utilitarista. Por último, considerando-se o viés pelo qual propõe o manejo dos conflitos, tais doutrinas acentuam o caráter preventivo dos direitos constitucionais. ${ }^{.}$

2. As doutrinas intergracionistas enfatizarão outros cinco aspectos. Em primeiro lugar, seu ponto de partida será o argumento econômico, observando que transnacionalização da produção e a integração dos mercados teriam como corolário a necessidade de harmonização das instituições de mercado. Em segundo lugar, com os mercados caminhando para a globalização, surgiria uma necessidade de se resguardar as comunidades nacionais, num movimento que buscaria preservar o pluralismo de opiniões e a organização política doméstica - por meio de um manejo político da integração, coordenado pelos governos nacionais. A terceira característica advém da anterior e se relaciona com a valorização dos espaços domésticos de deliberação. A

Considero que englobam estes elementos as doutrinas professadas por Petersmann (1991. 1998. 2000. 2002. 2002b). que considero um modelo coeso e exemplo paradigmático, além de outros libertários como ('harnovitz (2001). Schneider (1998), Dunoff (1999) Benvenisti (1999) e Bronckers (1999). 
quarta frisa o papel das regras da OMC em promover a cooperação entre as comunidades nacionais. A quinta característica, que se relaciona com a solução de controvérsias, ressalta o papel das regras e instituições multilaterais em fragmentar os conflitos, identificando e isolando seus elementos de modo a promover uma resolução escalonada - o que minimizaria suas proporções. ${ }^{5}$

3. As doutrinas juridico-sistêmicas se caracterizarão pelos seguintes elementos. O primeiro é o pragmatismo metodológico, que envolve a valorização dos postulados metodológicos do direito, da linguagem jurídica, da técnica jurídica e das construções doutrinárias existentes. $O$ segundo elemento importante na sua caracterização é conseqüência direta do anterior: estas doutrinas vêem os procedimentos e o devido processo legal como fundamentos da legitimidade do Direito Fconômico Internacional. Daí que, como terceiro elemento, aparece a ênfase nas funções estabilizadoras das regras - a segurança e a presibilidade das relações econômicas e jurídicas seriam alçados a valores dignos de constitucionalização. Em seguida, a litigiosidade e a face judicante do direito da OMC firmam-se como mola propulsora para 0 adensamento da malha jurídica, posto que se ressalta a prática de solução de controvérsias. O corolário prático deste elemento é o viés curativo que assumem estas teorias, posto que justificam e legitimam a capacidade dos órgãos judicantes - o OSC, em especial - em navegar pela malha jurídica e propor soluções aos conflitos interestatais. ${ }^{6}$

('omo observação final, é necessário que se diga que certos instrumentos conceituais serão utilizados mais intensamente por cada uma das doutrinas, caracturizando-as, de certa forma. Assim, as doutrinas libertárias freqüentemente recorrerão à noção de direitos individuais para justificar sua visão de constitucionalismo; em seu turno, as doutrinas integracionistas pregarão que o processo de constitucionalização das relações econômicas internacionais ocorre por meio de criação

Identifico como integracionistas as doutrinas defendidas por Stephan (2002), Weiler (1991, 1995, 1998 e 2000), Coltier (2000) e McGinnis e Movsesian (2000).

6 Sob esta ótica, são juridico-sistêmicas as doutrinas de Abbot. Kéohane, Moravesik. Slaughter e Snida! (2000), Palmeter (2000). Cass (2001) e Zleptnig (2002). 
de instituições multilaterais e regras de supranacionais; por fim, as doutrinas jurídicosistêmicas encontrarão o constitucionalismo na importação de métodos de interpretação típicos do Direito Constitucional pelos tribunais internacionais. No primeiro caso o veículo privilegiado da constitucionalização serão os indivíduos; no segundo, os governos nacionais; no terceiro, os juristas.

3. Crítica das doutrinas constitucionalistas apresentadas

Como nota Krajewski (200l), a relação enfatizada pelos seus proponentes entre os sistemas de princípios constitucionais nacionais e direito internacional é sua maior virtude - mas também limitação. Ao interpretar o movimento de criação da densa malha de normas reguladoras do comércio internacional dentro do arcabouço conceitual surgido com o constitucionalismo europeu, os libertários trazem à discussão sobre a emergência de uma esfera internacional de governança a perspectiva dos direitos humanos - no sentido de direitos de dignidade, direitos contra a opressão. No entanto, isto é feito de maneira a assumir o estreito viés de um liberalismo individualista: a faceta normativa destas doutrinas implica o recurso a um conceito de Constituição em que uma dimensão essencial das relações econômicas internacionais - a ação coletiva - é colocada em segundo plano. Ao prescrever que o processo de constitucionalização das regras de comércio internacional se igualam à defesa de liberdades privadas contra o Estado, a dimensão da política internacional é excluída - Howse e Nicolaidis (2003) chegam a afirmar que se trataria de uma tentativa de "tirar a política fora da equação global"

Além disso, ao fundamentar a emergência do movimento constitucionalista no plano das relações econômicas internacionais numa revisão histórica das doutrinas da modernidade européia, os libertários abstraem a história institucional e intelectual que levou à formação das instituições que deram origem ao regime político internacional da atualidade. Isso quer dizer que o surgimento da OMC e das regras do comércio internacional em muito pouco tem a ver com as lutas européias do inicio da Idade Contemporânea contra o absolutismo, os privilégios e a opressão do Estado. Não foi um movimento que buscava reconhecer a dignidade de cada um dos homens. conquistando direitos civis e políticos inalienáveis, oponíveis contra os governantes. que levou à criação do regime de cooperação internacional incutido nos Acordos de Marrakesh.

Em verdade, sob o prisma da legitimidade, as doutrinas libertárias pecam no sentido de radicalizarem o argumento da imposição de restrições aos governos 
nacionais. Levado às conseqüências desejadas pelos autores. encarando-se as normas da OMC como obrigações fortes, direitos a direitos, o resultado é um compromisso em que um governo nacional não ata suas próprias mãos, mas, sim, as mãos dos governos e gerações futuros. Há, portanto, um desequilibrio entre as obrigações assumidas perante a Comunidade Econômica Internacional esta, globalizada - e a comunidade política local: a fundação daquela significaria a incorporação e assimilação plenas - com conseqüente deslocamento - desta.

O segundo tipo de constitucionalismo é menos utópico no sentido de levar em consideração o processo de integração econômica como motor do surgimento das regras de comércio internacional. No entanto, superestima a capacidade institucional (ao menos atual) da OMC. Ao vê-la como motor de uma harmonização das regras e integração de mercados, as doutrinas integracionistas esquecem que o processo de negociação continua sendo, na atualidade e nos termos do Howse e Nicolaidis (2003), uma "barganha interestatal baseada no consenso" A OMC não tem poderes regulatórios autônomos, como bem observa Holmes (2001); não conta com um aparelho burocrático das dimensões da União Européia nem de um Parlamento ou fórum permante de discussões. Os temas negociados só se transformam em tratados anexos à Carta da OMC se houver acordo nas rodadas de negociação.

Além disso, ainda que corretamente enfatizem a valorização das deliberações tomadas pelas comunidades domésticas em nível nacional, as doutrinas integracionistas idealizam a efetividade dos mecanismos supranacionais de coordenação e solução de conflitos. Isto quer dizer que, diferentemente do que tentam fazer crer os integracionistas, o mecanismo de solução de controvérsias da OMC não decide de modo a substituir a vontade da parte infratora - como faz a Corte Européia, com seu poder de execução de suas decisões - mas apenas determina se uma medida está em desacordo com as regras da $\mathrm{OMC}$ e, em caso positivo, autoriza o ofendido a procurar compensações caso a violação persista. O Órgão de Solução de Controvérsias pode somente concluir que uma medida é inconsistente com um acordo coberto pela OMC e recomendar que ela seja corrigida.

O ESC diz, em seu Artigo 19:

"Article 19: Panel and Appellate Body Recommendations

1. Where a panel or the Appellate Body cuncludes that a measure is inconsistent with a covered agreement, it shall recommend that the Member concerned9 bring the measure into conformity with that agreement. 10 In addition to its recommendations, the panel or Appellate Body may suggest ways in which the Mcmber concerned could implement thi recommendations.

2. In accordance with paragraph 2 of Article 3, in therr tindings and recommendations, the panel and Appellate Body cannot add to or diminish the rights and obligations provided in the covered agreement." 
Por último, as doutrinas jurídico-sistêmicas, apesar de serem relativamente mais consistentes do ponto de vista interno, padecem do defeito da insuficiência. Explicam otimamente um dos elementos essenciais do constitucionalismo da OMC - a emergência de regras, no sentido de "legalização" das relações internacionais. No entanto, desconsideram que ainda permanece e é igualmente essencial no sistema atual: a deliberação política. Ao pensar no surgimento de divisões de poderes e repartição de competências como sendo produto da atividade interpretativa dos órgãos judicantes da $\mathrm{OMC}$, as doutrinas jurídico-sistemáticas simplificam o processo histórico de consolidação e fundação da comunidade econômica internacional. Ainda que as normas sejam elemento essencial para entender o direito da OMC, o raciocínio jurídico e a aplicação da técnica estão demasiadamente limitados pelas considerações de oportunidade política. Isto quer dizer que a apreciação jurídica dos argumentos só tem lugar em momentos restritos dentro da OMC, sendo que sua legitimidade não pode ser justificada somente com o recurso ao exercício de sua capacidade de dizer o direito. $\mathrm{O}$ sistema ainda depende fortemente de sua capacidade de produzir bons resultados para se legitimar - a invocação de princípios de justiça e a característica impessoal das decisões judiciais (em que o que importa é a regra e o argumento, e não o seu portador) ıstão em rulação de dependência estreita com a deliberação política que não necessariamente se traduz em regras.

Tendo em vista as limitações das doutrinas juridicas acima descritas, a idéia de uma Constituição Econômica Internacional parece distante da realidade. As concepções libertárias, integracionistas e jurídico-sistêmicas padecem de sérias deficiências, no sentido de desprezar elementos institucionais importantes da realidade da regulação do comércio internacional: não são sensíveis o suficiente para captar a dimensão mais importante necessária para se postular a constitucionalização das relações econômicas internacionais, qual seja, a da legitimidade. A elas escapa a dimensão da deliberação política real e sua relação com as instituições existentes - sejam nacionais. scjam internacionais. Para que tal sensibilidade institucional seja reinserta no debate, será necessário que se reformulem os fundamentos do conceito de Constituição Econômica Internacional, de modo a recuperar seu sentido legitimante.

4. Constituição econômica internacional e a legitimidade da deliberação política internacional: Constituição e cooperação internacional

Dadas as limitações metodológicas do constitucionalismo inspirado na tradição liberal (expostas quando da crítica às teorias libertárias), do constitucionalismo 
de cunho federalista (expostas em suas duas vertentes - aquela baseada no processo de integração europeu e a outra, de natureza madisoniana - quando da crítica às teorias integracionistas), e do constitucionalismo de cunho técnico (expostas na crítica às concepções jurídico-sistêmicas), um novo fundamento metodológico terá que ser encontrado, que dê conta de compreender nos termos propostos o papel de uma Constituição. Em outras palavras, tal doutrina deverá entender a constitucionalização das relações econômicas internacionais como o estabelecimento de um compromisso que funda uma comunidade política - a Comunidade Econômica Internacional. As normas da OMC, então, poderiam ser entendidas como este compromisso na medida em que permitem a separação a esfera pública da esfera privada no âmbito internacional, criando a possibilidade de que a diversidade de interesses sejam legitimamente representados e possam. em sua real dimensão, ser colocados em debate de modo a serem tratados com a dignidade que merecem.

A preocupação com a necessidade de se estabelecer regras fundamentais que diferenciassem deliberações constitutivas de uma comunidade política daquelas ordinárias aparece nos Papéis Federalistas. "Uma Constituição é estabelecida pelo povo e inalterável pelo governo" Esta afirmação peremptória, defendida por Madison no Federalista Número 53, estabelece um vínculo indissolúvel entre legitimidade e deliberação política, no interior de uma comunidade política. Desta postulação, desejo retirar a icéia de que é a Constituição que define os limites dos poderes dos governos no que tange a formulação de políticas públicas. indicando até que ponto a esfera política poderá intervir nas vontades privadas. Desta feita. pensar numa Constituição Econômica Internacional equivale a pressupor uma Comunidade Econômica Internacional que, reunida e ciosa em determinar prospectivamente os termos em que a cooperação em seu seio ocorrerá, define regras que não poderão ser transgredidas sob pena de se eliminar 0 vínculo cooperativo sem o qual inexiste a comunidade.

Nesta linha, Goldstein (2000: 133-152) trata do fenômeno da cooperação internacional distinguindo dois casos. No primeiro. a cooperação é incontornável porque resultante de uma situação de harmonia entre as nações: o conflito é evitado simplesmente porque estas, agindo em seu interesse particular, facilitarão que outras nações atinjam seus próprios objetivos. Trata-se de um caso de coincidência de objetivos em que a ação individual de uma nação aproveita as outras. No segundo, entretanto, a cooperação não é automática, porque requer que as nações coordenem seus comportamentos antecipando as políticas, decisões e ações que serão tomadas por outros governos. Nesta situação, o resultado da interação é incerto posto que a decisão de um membro da comunidade afetará o conjunto de escolhas que terá o outro diante de si. 
Tendo em vista esta diferença, o grau de dificuldade que as nações enfrentarão no que tange a necessidade de coordenarem suas politicas públicas dependerá da estrutura de preferências dos atores. ${ }^{\delta}$

Regras constitucionais instituem uma comunidade política porque dão as condições básicas sem as quais a cooperação não ocorreria naturalmente. Oferecem, do mesmo modo, critérios para identificação de desvios que devem ser sanados caso os membros da comunidade desejem a subsistência desta. Dito de outro jeito, regras constitucionais permitem que se identifiquem claramente os limites do comportamento individual - dado que a não-dissolução ou não-disrupção da comunidade se impõe como valor primordial. Tal conclusão pode ser capturada através de recurso ao chamado dilema do prisioneiro, ${ }^{9}$ que descreve uma situação em que a interação ocorre sem que haja condições de mínimas de cooperação. Em verdade, a ação egoística dos atores, neste modelo. reflete um estado de anarquia em que dois agentes prejudicam-se mutuamente - não há condições mínimas de convivência pacífica. Neste exemplo, é possível notar que dois sujeitos, isolados e agindo egoisticamente, chegam a resultados negativos para ambos. Para que uma solução melhor seja conseguida, seriam necessárias regras que lhes incentivassem a cooperar. Pois se chamam regras constitucionais as que cumprem o papel fundar a cooperação.

Vejamos: imagine-se que dois suspeitos de um crime são interrogados $\mathrm{cm}$ separado. O que um dirá o outro não saberá. No caso de nenhum confessar o crime, ambos saem livres. No entanto, se um confessar, terá redução de pena por colaboração com a justiça - enquanto o outro terá de cumpri-la em sua integralidade. Se ambos confessarem, haverá redução de pena, apesar de não tão importante quanto a prevista para o caso anterior. Chamando-se os anos de cadcia de anos de vida perdidos algebricamente, dando a eles um valor negativo - a seguinte tabela pode ser montada:

O cxemplu que a Autora cita é a escolha de padrões tecnológicos intemacionais: sua adoção pode ser decidida apenas porque um standard é mais amplamente utilizado - i claro que um pais preferiria que todos os outros utilizassem o padrão por ele adotado mas, ao contrário, sua preferência mais forte recai sobre ter um padrão comum do que nenhum. Dai que regras assumem um papel diferenciado, não como imposiçōes de comportamento, mas como instituiçóes que facilitam a cooperação. Uma vez que se decide sobre um padrão, ncnhum dos outros países membros da comunidade tem incentivos para utilizar outro. Vide Goldstein (2000: 134-135).

- O dilema do prisioneiro é uma das alegorias mais clássicas de como se pode utilizar a teoria dos jogos para modelar decisões. No caso. segundo defíniçào $\mathrm{e} \mathrm{sm} \mathrm{sua} \mathrm{versão} \mathrm{mais} \mathrm{primitiva,} \mathrm{é} \mathrm{um} \mathrm{modelo} \mathrm{de}$ interação não-cooperativa entre dois jogadores que resulta em estratégias dominantes que implicam um equilibrio pareto-infirior. lide Watson (2002). 


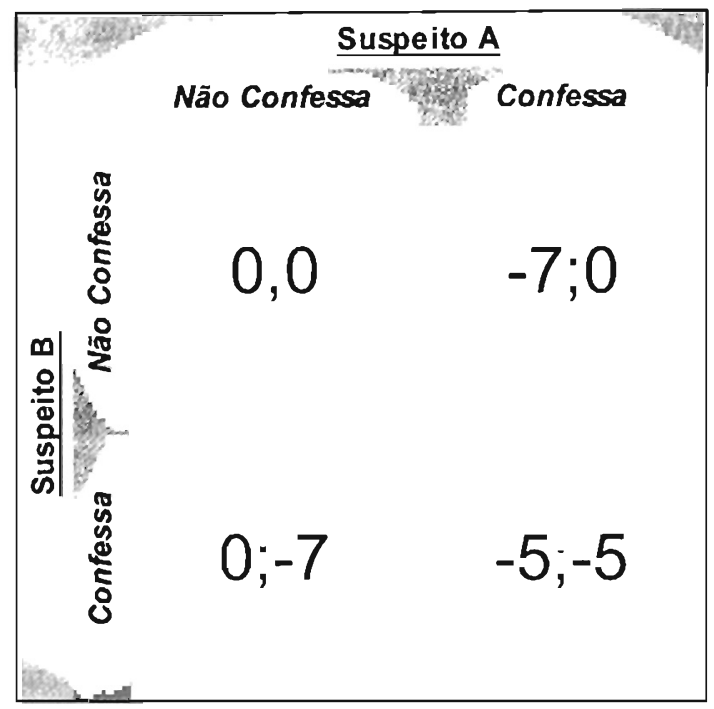

O melhor dos mundos para ambos seria aquele em que ninguém confessasse - nenhum dos dois suspeitos perderia anos de vida na cadeia. No entanto, como garantir que o outro não confesse? Isso porque, dada a possibilidade que o suspeito A confesse, o suspeito B perderia 7 anos de sua vida em liberdade - o que dá a B um incentivo para tentar salvar, pelo menos, 2 anos. $\mathrm{E}$ o suspeito $\mathrm{A}$, colocando-se no lugar de $\mathrm{B}$, pode fazer o mesmo raciocínio. Neste caso, ambos confessariam. E a conclusão mais surpreendente é que a estratégia dominante passa a ser a que leva a maior redução do bem-estar da nossa pequena "comunidade": ${ }^{10}$ ao todo, os dois prisioneiros perdem 10 anos, se ambos confessarem. Se apenas um deles o fizer, a comunidade perderá 7 anos. Por fim, se ninguém confessar, a comunidade não perderá nenhum ano.

\section{Constituição como compromisso que funda uma comunidade política}

Justamente, porque existe anarquia - e não comunidade - é que podemos verificar que existiria um equilibrio melhor." No modelo apresentado, não há nenhum vínculo cooperativo entre os dois prisioneiros - nenhuma comunidade foi constituída por meio de regras. Pois, no momento em que se retira o pressuposto da incomunicabilidade dos prisioneiros e se permite que eles possam discutir o que farão, aprendendo e

10 De lato, não existe comunidade neste momento porque o conceito de comunidade pressupõe cooperação * deliberação. Assim, o que se faz aqui é meramente um exercicio de agregação de resultados de dois atores individualmente considerados - e não. em verdade. medir a queda de bem-estar da comunidade relacionada a não-cooperação.

"Vide Keohane (1984:51-52) para os conceitos de anarquia, equilibrio de cooperação. Vide infra, sobre o conceito e uso de regras de cooperação e sua diferenciação de regras de muma convivéncia. 
negociando suu próximo movimento, comparando as opções e definindo ex ante as condições de sua cooperação. os limites de seus comportamentos egóísticos neste momento constitui-se uma comunidade. A partir deste instante, os membros da comunidade podem, dentro das regras de interação, buscar sua melhor opção.

Note-se que de modo nenhum se vincula aqui as regras que criam condições para a cooperação - e que, em conseqüência, constituem uma comunidade política - com os resultados da cooperação. Retornando à frase de Madison citada no início deste capítulo, o fato de o bem-estar da comunidade aumentar é uma questão de governo - e a constituição apenas permite que a comunidade exista e possa, caso assim decida, formar um governo. Assim. como afirma Sunstein (2001:6). o objetivo central de uma Constituição é criar as precondições para a existência de uma ordem democrática que funcione bem. na qual os cidadãos sejam capazes governarem a si mesmos. Esta ordem democrática tem como principais componentes dois dados fundamentais de legitimidade,quais sejam. (a) o prestar contas e (b) e um compromisso geral com o dever de fundamentar racionalmente nas deliberações. ${ }^{12}$

Uma tal orientação, que implica uma certa análise do conteuido das normas a que se quer chamar de Constituição, parece ser mais adequada por captar um elemento essencial do uso do conceito. no que se refere a uma Constituição: a idéia de que, uma vez que ela definitivamente existe, as deliberações no seio de uma comunidade não deixam de fazer a ela referência. Isso quer dizer que Constituições marcam tão profundamente a vida de certa comunidade política que adquirem o caráter de pressupostos para a deliberução. F.lster (2002) apresenta uma imagem bastante ilustrativa do tipo de papel que Constituições têm na deliberação politica. Ele se apóia no mito de Ulisses e as Sereias, em que o herói grego prende seus homens e ata-se ao mastro de seu barco para não se perder pelos feitiços das sereias ao ouvir seu canto, podendo realizar tranqüilamente a travessia do mar. Na alegoria, os membros de uma comunidade protegem-se contra arroubos apaixonados, ${ }^{13}$ mudanças de preferência e inconsistências temporais ${ }^{14}$ celebrando pré-compromissos - na forma de hands-tying.

12 Sunstein (2002: 7) apresenta tais expressōes. no original inglês, como "political accountability with a high degree of reflectiveness" e um "general commilment to reason-giving"

13 "Paixão", como razão para a emergência de pré-compromissos, ć apresentada por Elster (2000: 7-24) num sentido lato que inclui tanto emoções quanto sentimentos viscerais. Tais arroubos são considerados como da natureza humana e portam grande influência no processo deliberativo ordinário.

14. Inconsistências temporais são comportaınentos que implicam no curto prazo, ganhos, mas, no longo prazo. perdas. Assim, ocorrem quando uma politica planejada para o futuro não é a melhor quando este futuro acontece (Elster 2000: 24-25). Na literatura especializada, aponta-se cm duas direçōes: (1) inconsistências relacionadas com subvalorização dos efeitos futuros e sobrevalorizaçào dos efeitos presentes no bem-estar individual de certos tipos de açōes; e (2) inconsistências relacionadas com comportamento estratígico dos agentes que, no caso de antevirem ganhos individuais maiores do que aqueles que sobrevècm de compromissos assumidos e promessas feitas, rompem com o que foi acordado. 
Por meio deles, elas afastam de seu alcance um conjunto de alternativas, fazendo-as mais custosas ou as tornando indisponiveis instantaneamente -.- limitando. por conseguinte. o exercício de livre-escolha.

Antes de prosseguir, é necessário diferenciar a definição que pretendo de Constituição daquela apresentada por outros estudiosos. Entre as definições paradigmáticas de Constituição que penso ser insuficiente está a de Buchanan (1977: 292). Ele. de outro modo, define Constituição como "a set of rules which constrain the activities of persons and agents in the pursuit of their own ends and objectives" apontando para um determinado conteúdo material para as Constituições que têm a ver com a seleção de preferências dentro de uma comunidade. Esta versão não se coaduna com a idéia que será aqui discutida, sendo necessário que se façam algumas correções. Expurgando alguns pressupostos ideológicos fortes de sua teoria, colocando o fato de a deliberação poder acontecer como um bem em si mesmo (como faz Sunstein, 2002: 7) e retirando a necessidade de que os resultados da deliberação sejam maximizadores das utilidades individuais, talvez possamos chegar a um conceito mais palatável.

Em primeiro lugar, o quê pessoas e agentes ${ }^{15}$ perseguem (e que Buchanan chama de "fins e objetivos próprios") é a melhoria do bem-estar social - e não-somente o individual. Esta definição congrega a dimensão política da busca do aumento do bemestar social (social welfare), incorporando o elemento procedimental - a forma como agentes e pessoas se relacionam. Aliás, isto considerado, o que o Autor chama de "pessoas" torna-se aqui "membros da comunidade" - uma Constituição não é apenas o regulamento essencial de um bando de pessoas, mas, sim, de pessoas vinculadas a uma Comunidade. Ora, a Constituição Econômica de que se tratará aqui é estritamente ligada a duas preocupações: a (i) primeira, de natureza explicativa, foca o modo como as relações econômicas se organizam e como as instituições moldam estas formas de organização; a (ii) segunda, de natureza normativa. tem como cerne a procura da melhor forma de organizar as relações econômicas internacionais, de modo a obter um ambiente econômico de alta qualidade, que permita a integração de economias nacionais ao sistema multilateral de comércio.

Em segundo lugar, não se pode esquecer que "fins e objetivos" dos membros da sociedade não podem ser definidos de antemão - são produtos da expressão de opiniões, de debates e decisões. Assim, como regras de garantia de deliberações relativas ao bem-estar da comunidade, as normas de uma Constituição Econômica devem permitir as ações individuais dos membros de uma comunidade sejam

is A noção de agent í técnica e tem um significado especifico na cconomia politica; tem a ver com a idéia de mandato ou representação - agente é aquele incumbido de agir pelo incumbente no nome e beneficio daquele. Ela se contrapõe ao principal, que é o mandatário ou representado. 
consistentes. Em vista disso, adoto a definição de que uma Constituição Econômica seria um corpo consistente de regrus que fundam a cooperaşão democrática entre os meinbros de uma comunidade definida.

\section{Propriedade privada, sociedade civil e Constituição Econômica}

Segundo se argumenta neste texto, as regras do comércio internacional surgidas com o advento da OMC devem ser entendidas como normas da Constituição Econômica Internacional. Elas foram convencionadas de modo a criar um ambiente internacional propício à cooperação econômica e a deliberação política, em que os países que assim o desejarem integrem suas cadeias produtivas entre si, tendo em vista melhorar as condições de vida de suas populações em suma, desenvolverem-se. Tal papel. no plano infranacional, é desempenhado pelas Constituições nacionais. Para estender essa tese ao nivel das relações internacionais, será necessário (a) fazer a prova da necessidade da tese, expondo em linhas gerais as caracteristicas e funções das Constituições; (b) verificar sua suficiência, assinalando em que medida tal tese aplica-se ao direito das transações econômicas internacionais.

\section{(a) Constituições econômicas}

Para explicar como as Constituições determinam a separação das esferas pública e privada, e a relação disto com a melhoria das condições de vida. um bom começo seria traçar a relação entre democracia e direitos de propriedade. Como salientou-se. equipara-se aqui melhora das condições de vida com desenvolvimento - o que não incorpora apenas a dimensão econômica, mas, sim, melhoria das condições institucionais que facilitam a deliberação.

Sunstein (1991: 5 e ss) apresenta uma distinção básica entre propriedade privada e economia de mercado. Num sistema de propriedade privada, as consequiências do uso, gozo e fruição relativos ao direito de propriedade incumbem seu titular. No caso da economia de mercado, o elemento distintivo é a possibilidade de se alienar livremente a propriedade. Em países desenvolvidos, ambos caminham de forma copulada; nos paises em desenvolvimento, isto não necessariamente acontece $^{16} \ldots$ donde a importância

16 Segundo o Autor, são quatro os motivos pelos quais propriedade privada e prosperidade econômica estão relacionados:

i Enquanto um sistema em que a propriedade não é privada leva à ineficiência e desperdício. a garantia de direitos de propriedade cria incentivos para que se cultivem e usem estes direitos - já que os ganhos serão totalmente apropriados pelo proprictário.

ii I'm sistema de propriedade privada executa uma função de coordenação, garantindo que as preferências milhares de pessoas sejam refletidas pelo mercado. Enquanto o sistema de planificação gera oferta insuficiente ou demasiada. a propriedade privada permite uma melhor alocação de recursos. 
da diferenciação entre os estágios de desenvolvimento. ${ }^{17} \mathrm{~A}$ ambos, agrega-se mais uma garantia: a democracia.

Porém, o Autor nota de pronto uma certa tensão entre democracia e direitos de propriedade. O mercado pode impor severos custos a curto termo (como desemprego e inflação) que fazem grande a tentação pela flexibilização dos direitos de propriedade. No entanto, a eliminação completa destes destrói a democracia porque deturpa a relação entre o cidadão e o Estado. A segurança pessoal e a independência do indivíduo em relação ao governo só são garantidas quando os direitos de propriedade são protegidos por instituições públicas, não ficando os direitos individuais à mercê da vontade do ocupante do governo (Sunstein 1991: 8).

Neste sentido, a existência de uma esfera pública não é metafísica, mas tem natureza politica; a criação (jurídica) de uma esfera privada é produto de uma ação do Estado, como parte do processo de criação de uma sociedade civil e de uma ordem de mercado (Sunstein 1991: 9). Subsistindo esta separação básica entre o público e o privado, seu conteúdo (o conteúdo dos direitos, incluindo aí a definição exata dos limites do direito de propriedade) pode ser sempre criticado, sendo freqüentemente sujeito ao processo de redefinição democrática (Sunstein 1991:9-10). O direito de propriedade, na verdade, é uma das instituições que são condições necessárias para a existência de uma esfera privada separada da pública. Ele se conecta com (i) o governo das leis (rule of law), ${ }^{18}$ (ii) devido processo legal, ${ }^{19}$ (iii) liberdade de expressão ${ }^{20}$ e (iv) certeza jurídica ${ }^{21}$ (Sunstcin 1991: 9-12).

iii Assegura a intemalização de externalidades: enquanto em regimes de propriedade pública ou coletiva as pessoas tèm incentivos à superexplorar os recursos - e não à conservá-los, usando-os na medida de sua utilidade - nos regimes de propriedade privada o problema de ação colctiva é resolvido.

iv Investimento e iniciativa são incentivados, jà que os cidadãos não correm o risco de ver seu trabalho perdido e seu esforço desperdiçado por conta de um ato unilateral do governo ou de uma decisão da maioria que nâo leve em conta a vontade da minoria.

17 É importante dizer que Sunstein (1991: 5) frisa que estas asserções não se assentam sobre um conceito egoistico de natureza humana - o desejo de adquirir bens pode ser, em sua opinião, emincntemente altruistico - pessoas podem querer dar tais bens a outros, sem guardá-los. $U$ impulso parece ser, portanto. não de entesouramento (conservar scu patrimônio), mas unicamente de decidir por si mesmo a destinaçãi) de seu esforço - uma garantia de liberdade.

18 Entendido como obrigatoriedade na existência de lei prévia para permitir a intervenção do governo nos assuntos privados.

19 Entendido como proscrição da punição estatal arbitrária (justificada por leis vagas, ou por nenhuma lei). A puniçàu a que se faz referência não necessariamente precisa ser a criminal - pode ser a expropriação, ou qualquer outra forma de pressào yue o governo possa fäer sobre o cidadão, utilizando-sc até de nlexibilização de seu direito de propriedade.

20 Entendida como vedação do cuntrule. pelo govemo, dos meios de comunicação e formas públicas de expressão.

21 Entendida como garantia contra a instabilidade das regras, notadamente contra a quebra de contratos. ações populistas ad hoc, constante redefinição de direitos de propriedade de lorma não-democrática. 
A defesa dos direitos de propriedade não é, no entanto, uma defesa da imobilidade social - é plenamente compativel com políticas redistributivas, tanto por meio de criação de riqueza quanto por mecanismos de Estado-Providência. Isso ocorre por uma única razão: o que está em jogo não é o resultado econômico do estabelecimento dos direitos de propriedade, mas o resultado político. Daí que surge a diferenciação entre (a) a redistribuição de renda (mera realocação de recursos de um ente privado a outro em que o governo entra como parte neutra) e (b) ingerência nos assuntos privados (relativização dos direitos de propriedade que visa a realizar fins governamentais - e não-sociais). No primeiro caso, há obediência à regra do Ótimo de Pareto; ${ }^{22}$ no segundo, não.

O que se depreende disto, no final das contas, é que existem dois elementos em conflito permanente: (a) o princípio econômico (busca da eficiência alocativa) e (b) o princípio democrático (a regra da maioria). A separação dos domínios público e privado confina cada uma das duas ordens à sua esfera de influência; mais do que isso, faz com que haja um intenso interelacionamento entre ambas, através do qual os limites das duas esferas são constantemente redefinidas.

(b) Garantias constitucionais

Como pode ser notado, no sentido buscado por Sunstein (1991) uma Constituição é o marco institucional que engendra a separação entre os domínios público e privado. De fato, é a consubstanciação de um processo político por meio de regras do Direito, no qual um limite à ingerência do Estado sobre os assuntos privados é firmemente estabelecido.

Para verificar se as normas do sistema multilateral de comércio se encaixam na concepção de Constituição Econômica apresentada, é preciso que se tenha em mente quais provisões em particular são essenciais para garantir o estabelecimento dos fundamentos econômicos da res publica. ${ }^{23}$

22 O Ótimo de Pareto é um conceito da economia do bem-estar. Ele define um equilibrio distributivo em que, numa comunidade. para que se aumente o nivel de bem-estar de uma pessoa. deve-se obrigatoriamente reduzir o de outra.

23 Sunstein (1991: 17-23) apresenta as seguintes provisões:

$i$. "Rule of law" - assegurar que um governo não possa tomar nenhuma atitude contra um de seus cidadãos a não ser que exista lei prévia, pertinente e explicita. Visa a assegurar que o cidadão exerça atividade econômica sem nenhum medo de vê-la e a seus resultados condicionados à política.

ii. Garantias matericis do direito de propriedade - são de duas ordens:

Garantias contra a expropriação sem devida compensação justa;

a. Garantias contra a expropriação sem devido processo legal (que inclui (I) exigência de argumentação jurídica sólida por parte da autoridade pública e (II) direito de ser ouvido e se defender).

iii.Proteção dos contratos.

iv. Liberdades de exercicio de atividade econônica:

a. Garantia pessoal - livre exercicio de oficios e profissôes, livre-iniciativa. 
Em primeiro lugar, Hoeckman e Kostecki (2001: 25) afirmam que o a OMC tem dupla função: (i) a de determinar regras de conduta e (ii) a de servir de fórum de troca de compromissos políticos. No primeiro (i) caso, encontramos a garantia do Rule of law: a codificação das formas de intervenção, com definição através de acordo entre todas as partes contratantes sobre as formas lícitas (mecanismos e hipótese) que se utilizarão para estabelecer controles sobre a atividade econômica responde à necessidade das regras serem previamente acordadas. No caso (ii) incluem-se as disposições que obrigam os países a estabelecerem missões permanentes, comunicando-se e trocando informações de modo a publicizar o maior número de informações possíveis para que possam ser identificados potenciais efeitos negativos de políticas públicas. É um engenhoso mecanismo desenhado para obrigar os governos nacionais a prestarem contas uns aos outros e negociarem entre si, apresentando razões de suas decisões, explicando e justificando suas políticas públicas.

Em segundo lugar, a forma como os governos nacionais intervêm na esfera privada, no plano internacional, tem a ver com a imposição de restrições às decisões privadas de relocalização da atividade econômica. ${ }^{24}$ Isto acontece por meio de (1) imposição de barreiras alfandegárias e não-alfandegárias ao comércio de bens e serviços, (2) imposição de controles sobre os investimentos e (3) relativização dos direitos de propriedade intelectual. São notadamente ingerências sobre o direito de propriedade e sobre a garantia de contratos, que implicam em redução da esfera privada de ação. Ora, o GATT, GATS, TBT. NTB, TRIMs e TRIPS podem ser vistos como limites acordados entre os governos, de forma a restringir a ingerência dos governos nacionais sobre os direitos de propriedade e sobre os contratos.

Em terceiro lugar, as outras garantias aduzidas por Sunstein (1991) implicam o que a moderna doutrina chama de accountability - regras que obrigam os governos a prestarem contas de suas ações de forma a tornar o debate decisório transparente, fazendo com que as conseqüencias e resultados pretendidos scjam realmente efetivados. Isto é, manejo responsável e cristalino dos recursos públicos,

\footnotetext{
b. Direito de escolher uma ocupação.

c. Proibição de trabalhos forçados.

v. Proibição de monopólios - exceção: monopólios naturais e os relativos a atividades-meio para execução de funções estatais.

vi. Não-discriminação entre empresas públicas e privadas.

vii. Liberdade de locomoção no interior do pais e ao exıerior.

viii. Constituição fiscal:

a. Eliminação de tarifas.

b. Orçamento equilibrado.

c. Restrições aos poderes de tributar.

d. Fim dos controles sobre exportações e importações de moeda.

it Vide Schaffer. Earle e Agusti (2002: 20-21)
} 
assim como da tramitação das propostas e projetos das deliberações, no final das contas, desde a fase de apresentação das preferências, discussões, interesses envolvidos, aprendizado institucional e correspondência entre o consenso e a efetivação da medida. Ora, a aplicação do Princípio da Transparência na OMC tem o mesmo valor - deixar às claras e ao alcance da Comunidade as políticas públicas, interesses e ações dos governos nacionais, em nome de suas populações e perante a Comunidade Internacional.

7. Regras de competição versus regras de cooperação intre as nações

Uma das principais diferenças entre o GATT 1947 e os Acordos da OMC é que, enquanto estes são obrigatórios a todos os membros, abrangentes e geridos de forma integrada, nas regras estipuladas no GATT 1947 inexistia um grau de institucionalização que permitisse que se considerassem existentes pré-compromissos suficientemente fortes que implicassem a limitação dos conjuntos de alternativas disponíveis aos países em termos de políticas comerciais. “ Como afirmam Trebilcock e Howse (2002: 31), o G ATT era caracterizado por um conjunto de medidas temporárias e soluções ad hoc. Sendo assim, não eram regras decididas e compromissos assumidos, ambos ex ante, que serviam a limitar os comportamentos dos atores, mas, sim, considerações pragmáticas relativas ao poder econômico de um Estado. A solução de controvérsias havia sido deixada para ser introduzida no sistema por meio da OIC, não havendo no GATT nenhuma remissão a algum órgão multilateral adjudicante, seja ele criado especificamente para os fins da regulação do comércio internacional, seja sob a forma de extensão da competência da Corte Internacional de Justiça (Trebilcock e Howse, idem).

Assim, afirma-se que, enquanto o GATT 1947 estabelecia um regime em que regras mínimas de convivência mútua foram acordadas, na OMC o que impera é um regime em que regras de coopcração econômica são a tônica. Regras de convivência pacífica são diferentes de regras de cooperação. Enquanto as primeiras pressupõem o acordo em torno de standards mínimos que possibilitem a não-aniquilação mútua, as segundas têm a ver com um compromisso tendo $\mathrm{em}$ vista o atingimento de um equilibrio que implique o maior bem-estar possivel, dentro de uma deturminada comunidadc. Se se considerar o comércio internacional, pode-se dizer que, do primeiro grupo, fazem parte as regras que dizem respeito ao princípio da não externalização de problemas econômicos domísticos." No segundo caso, estão as regras que tornam possivel a

25 Todos estes pontos serão demonstrados infra, quando da reconstrução intelectual e institucional dos regimes de gestão do comércio internacional.

26 Tais regras não criam uma situação em que os paises são impingidos a coopcrar. Ao contrário, elas criam um arranjo institucional em que. se para resolver um desequilibrio econômico um pais estiver diante de duas politicas públicas (i) uma implicando que os custos do ajuste serão suportados apenas pela 
integração econômica, criando um ambiente em que prospere a interdependência entre os países e em que agentes privados possam organizar suas cadeias de produção de modo a aproveitar otimamente as diferenças de dotação de fatores existentes entre os países. ${ }^{27}$

A interpretação de uma Constituição como instituição fundamental (que funda, baseia, registra e serve de marco) para o desenvolvimento das relações econômicas implica que as regras do direito das transações econômicas internacionais criam o ambiente em que tais transações ocorrem. Isto requer que as escolhas feitas no seio da Comunidade Econômica Internacional reflitam em certo grau o caráter cooperativo que é a ela inerente. Se isto é assim, a leitura mais correta dos acordos da OMC seria aquela que apontasse para um meio de maximizar o bem-estar da comunidade internacional levando em conta a lógica econômica do desenvolvimento, conforme exposto supra.

Tomadas em conjunto, as regras da OMC são regras de cooperação, reguladoras das trocas internacionais e concebidas como a moldura institucional que deve incentivar estratégias de integração econômica pela via democrática. O que nos levaria a enxergar a abertura dos mercados em âmbito global não como um benefício per se, mas em termos de racionalização dos processos produtivos em vista da melhoria do bem-estar. Os paises devem baixar as tarifas não pelo simples fato de terem se comprometido a fazê-lo, mas porque a redução daquelas faz parte de um processo de reorganização da atividade econômica que leva a melhoria das condições de vida da comunidade internacional - ou seja, faz parte de uma estratégia nacional de

comunidade doméstica e (ii) outra implicando a repartição de custos de ajuste entre a comunidade doméstica e a comunidade internacional -- èn condições de não-coopcração. seja mais custoso (ou menos proveitoso) ao govemo deste pais adotar uma medida do tipo (ii). Nesta formulação, isto não aconteceria na ausincia de tais regras. Em molduras não-cooperativas, todas as ações são consideradas individualmente, perseguindo objetivos individualisticos. Vide Watson (2002: 2-3).

Tais regras pressupõem a existência de, pelo menos, mais um nivel de escollha em comparação à situação de não-cooperação (convivência mútua). Além de ter cscolhido entre repartir ou não o custo do ajuste interno do pais com a comunidade internacional - decidindo pela não internacionalização de problemas domésticos o governo deve cscolher entre duas políticas: (i) uma em que a solução encuntrada beneficia somente seu respectivo país e (ii) outra cujos beneficios externer-se-iam à comunidade intcrnacional. $\mathrm{Na}$ moldura da cooperação, as ações são consideradas conjuntamente. perseguindo objetıvos coletivos. Vide Watson (2002: 4). 
aspecto: não se tenta aqui olhar o sistema OMC através da lente das relações de causalidade (ser - plano da explicação) mas, diferentemente, buscando uma interpretação (dever-ser - plano da justificação). ${ }^{31}$ Não se trata de discutir como o comércio internacional melhora a vida das pessoas, mas sim como interpretar as regras do comércio internacional de modo que elas a melhorem. Assim, seguindo a explicação de Voigt (2000: 531), as regras que trazem conseqüências para cada membro da comunidade internacional só podem ser tomadas como vantajosas se cada membro da sociedade voluntariamente concordou com elas. ${ }^{22}$

Este postulado leva a outros dois: ${ }^{3 i}$

É possível descobrir as escolhas dos cidadãos - os cidadãos têm consciência (ou podem chegar a adquiri-la) de suas respectivas curvas de utilidade. é possível traçar um mapa de preferências, estas são transitivas (podem ser valoradas de forma a serem comparáveis) e - mais importante eles manifestam-nas;

O Estado é o veiculo pelo qual os cidadãos manifistam sua vontade - a vontade estatal representa a vontade popular. os governos nacionais, ao assumirem obrigações, concordarem com regras e discutirem-nas no seio das instituições internacionais, expressam a vontade de sua população.

Interpretar as regras que regulam as relações econômicas internacionais, conseqüentemente, implica entender os acordos que estão no fundamento daquclas como escolhas ótimas, nas quais a situação de todos melhora, sem exceção. Países só

Buchanan (1991: 5 e ss.), ao tratar da diferenciação daquilo que ele chama de Economia Constitucional para a Economia Ortodoxa ou Não-Constitucional (Constitucional Economics e Nonconstitutional kionomics. respectivamente) diz que ambas envolvem o estudo de escolhas dos indivíduos. No entanto, enquanto a Economia Ortodoxa trabalha com a questão das escolhas feitas dentro de um certo esquema de restrições, postuladas como impostas exogenamente sobre aqueles que escolhem, a Economia Constitucional trata das escolhas relativas aos esquemas di restrições em si considerados.

32 Voigt traz um principio há muito já conhecido da teoria politica. Ele loi proposto por Buchanan e Tullock (1962), sob uma ótica estritamente de escolha individual, numa perspectiva de racionalidade instrumental. Rawls (1971) retomou-o na tentativa de universalizar este insight, aumentando as exigências sobre os individuos, a ponto de transformá-lo num principio moral. it interessante notar que em ambos a possibilidade de consenso depende de como os individuos lidam com a informação. Na formulação de Buchanan e Tullock (1962: 78), a restrição à escolha vim na forma de um viu de incerteza (veil of uncerlainty), que impedc os individuos de fazerem previsões de longo-prazo sobre sua posição sócioeconòmica. Esta incerteza tem uma natureza empirica - os individuos não podem, devido ao fato de serem consciências limitadas, prever todas as conseqüencias de suas escolhas. Já no caso de Rawls, os individuos sào compelidos a escolherem tendo diante de si o véu da ignorància (veil of ignorance). Este é uma restrição de natureza moral - os individuos fazcm suas escolhas como se (as if) não pudessem saber sua posição sócio-econòmica no futuro.

De modo a não entrar numa digressão sobre a natureza c legitimidade da representação no plano nacional. assumo para os efeitos deste texto a posição de Dworkin (1997: 151 e ss), para quem u Estado é a comunidade personiticada. no sentido dos doss postulados que seguem. 
acordariam em negociar concessões, celebrar tratados e convenções e participar do sistema multilateral de comércio se a condição de vida de seus cidadãos melhorasse. Neste sentido, o fato de os paises terem se obrigado às normas da OMC deve ser interpretado de forma a expressar um compromisso de todos com a busca pelo atingimento do ótimo de Pareto situação em que é impossível melhorar a situação de um indivíduo sem deteriorar a de outro.

Isso dizer é afirmar que tais regras definem uma sólida repartição entre o espaço público e o privado, já que ditam os limites de intervenção dos governos nacionais sobre a vida dos cidadãos e sobre as comunidades nacionais concernidas. Como normas que permitem a busca pelo bem-estar da comunidade internacional, elas contêm o arroubo de um grupo de cidadãos (representados por um governo) no sentido de melhorar sua situação em detrimento do resto da comunidade. As instituições do sistema multilateral de comércio permitem que a atividade econômica e a res publica não se confundam por meio de garantias, acordadas pelos Estados (em última instância, por todos os membros da comunidade internacional), da sociedade civil e da propriedade privada contra a ingerência dos governos sobre o domínio privado - papel este segundo Sunstein (1991: 4), das Constituições.

9. Interdependência, regras e criação do ambiente econômico internacional

Jackson (2002: I e ss), descreve o ritmo de desenvolvimento da interdependência internacional como head spinning. A atividade cconômica se desprende dos limites territoriais nacionais; os governos encontram dificuldades para implementar de políticas públicas; o fator internacional não pode mais ser considerado como um dado exógeno à economia nacional. De fato, a reorganização da alocação de recursos, fatores de produção e fluxos (tanto de mercadorias como de capitais) alterou o modo como as pussoas vivem, as exigências que elas fazem a seus governos e a forma como esses governos intervêm em suas realidades. ${ }^{34}$

Ainda que economistas ${ }^{35}$ busquem as causas dessas mudanças (i) na tecnologia (transportes e informação), (ii) na internacionalização do capital via

34 Com modo de vida das pessoas. refiro-me à dimensão das relaçôes sociais no seio de uma comunidade. Com exigências que elas fazem a seus governos, refiro-me à dimensào đa participação política no seio de uma comunidade. Com forma como esses governos intervìm em suas realidades, refïro-me à dimensão das políticas públicas. Existem diversos modelos de análise de tais perspectivas e eu poderia citar aqui vasta bibliografia. No entanto, apenas a titulo de curiosidade e para não escapar ao tema desta monografia. sugere-se apenas uma visita a Przeworski (1990). I sta reconstrução será feita ao longo da parte II desta monogratia.

35 Para uma história cconômica destas modificações vidi. entre outros. Bordo, Taylor c Williamson (Forthcoming) e Adda (1998). 
investimentos direitos estrangeiros (FDI), (iii) nas novas relações produtivas advindas na escala global de competição e (iv) na ausência de eclosão de conflitos militares de escala global no Pós-Segunda Guerra Mundial. é patente e óbvia a contribuição das instituições internacionais erigidas durante a última metade de século. Sem elas. não poderia ter sido criado o ambiente (environment) que permitiu a nova organização internacional. Jackson (2002:7) chega a afirmar que mesmo os avanços científicos teriam pouca influência caso os governos nacionais tivessem resistido às mudanças. Gilpin (2001:3) salienta, no mesmo sentido. que este ainda é um mundo em que as políticas e economias nacionais ainda são muito importantes. Governos ainda importam. Importam porque definem as regrus que pautam a integração econômica.

Tendo em vista este processo de integração, pode-se dizer que, ao acordarem em regras que regem as relações econômicas internacionais. os Estados acabam por criar uma série de incentivos para a melhoria das condições de vida existentes entre os países participantes e suas populações. No entanto. tudo isso tem um preço. O mesmo Gilpin (2001: 8-9), por exemplo, confronta duas visões do processo: (i) aquela que recebe com felicidade o final economia internacional dominada pelos Estados e a emergência daquela dominada pelo mercado e (ii) aquela que afirma serem grandes os custos da globalização economia. com o aumento da desigualdade de renda - entre e no interior das nações , os altos e crônicos niveis de desemprego nos países desenvolvidos, a degradação ambiental e as crises financeiras causadas pelos capitais voláteis.

Fste movimento de integração econômica se reiniciou no Pós-Guerra entre os ditos países ocidentais desenvolvidos. Incorporou os chamados NICs (newly industrialized countries) na segunda metade dos anos 70 e durante toda a década 80 e, neste início de milênio, ameaça se estender a um universo muito maior de nações, incluindo o que era o antigo mundo soviético e países de dimensões continentais como a China. Indonésia e Brasil. As correntes mencionadas supra por Gilpin (2001), mesmo discordando quanto à valoração de seus efeitos, concordam em um ponto: o processo não poderia ocorrer nem continuará a se aprofundar senão através da criação de regras. Hoeckman e Kostecki (2001:9) apontam que o GATT, muito mais do que um instrumento de abaixamento de tarifas entre paises desenvolvidos, significou a criação de uma complexa rede de direitos e obrigaçñes regulando as relações internacionais de comércio.

A idéia de Constituição Econômica Internacional traz consigo a imagem de um acordo entre os concernidos permite o debate sobre o nivelamento do campo de ação (field leverage) e sobre o estabelecimento das regras fundamentais sobre as quais 
erigir-se-ão as relações econômicas entre os governos. suas populações e o mercado. Destarte. o aspecto essencial a ser retido é o de que a existência de normas tem, entre outras, a função de criar um ambiente em que as relações econômicas possam se desenvolver com segurança e do melhor modo possivel. ${ }^{36}$

10. O conteúdo do pacto econômico internacional: integração é diferente de abaixamento de tarifas?

Pois, pergunta-se. qual é o conteúdo deste novo pacto entre os Estados tendo em vista a busca de maior bem-estar social ao redor do mundo? Em primeiro lugar, o que se pode dizer é que o resultado dos longos anos de negociações é um emaranhado de regras para compatibilização de políticas públicas: os Estados nacionais criaram mecanismos institucionais para viabilizar a atividade econômica no plano internacional. Em outras palavras, as regras que compõem o pacto fundamental entre os Estados são, em grande medida, regras de integração econômica - e, neste sentido, constituem o espaço econômico internacional, harmonizando, institucionalizando-o e, mais importante, garantindo a segurança das relações econômicas entre entes privados. Elas podem ser entendidas como um pacto entre os governos, cujo objetivo é evitar que medidas unilaterais dos Estados, sob a forma de ingerência indevida prejudiquem os fluxos econômicos. Os governos nacionais agem em nome de seus cidadãos para acordar regras multilaterais que evitem que outros governos prejudiquem seus particulares, seus consumidores, suas empresas, enfim - suas economias. Têm como objetivo criar um ambiente econômico sadio, do qual seus cidadãos possam tirar o melhor proveito possivel. $^{3 i}$

Por exemplo, acordos que contemplam tetos (ceilings) tarifários fixação de tarifa máxima (bound rate), além de equalizar as condições em que produtos

36 A noção de ambiente se refere ao conjunto de instituições que melhoram o nível de vida de uma populaçãu. A expressão melhor modo possivel implica, neste texto, na busca de critérios objetivos para identificar a melhoria das condiçōes de vida. Dai, o conceito de desenvolvimento.

37 Este período contém duas idealizações importantes. A primeira é a de que os governos sempre agem de modo a garantir o bem-estar de sua populaçào. Em outras palavras, pressupóe-se aqui que a vontade estatal é a mesma que a vontade popular - os Estados e seus representantes internacionais defendem posições quc estão de acordo com os anseios de seus cidadãos. A segunda idealização é a de que a vontade dos cidadãos expressa a opção que, individualmente para cada um deles, maximiza seus respectivos bemestares. De outro modo dito, postula-se que os cidadãos têm consciéncia das medidas que aumentam seu bem-estar, podendo compor um mapa de preferèncias que reflete uma situação em que eles cstariam o melhor possivel. no todo. Essas idealizações só são aqui colocadas porque se pressupõc um processo democrático de deliberação. Isso quer dizer que as preferências dos cidadãos não sào medidas no sentido de pressuposições. mas são descobertas no debate réal. na argumentação pública. 
nacionais competem com estrangeiro, ${ }^{38}$ têm a função de cvitar que os governos nacionais que acordam reduções tarifárias voltem atrás em suas concessões - em outras palavras, evitam que políticas públicas, adotadas num só movimento da caneta dos governos, levem à destruição de relações econômicas consolidadas. O sentido juridico desta proteção é, portanto, oferecer um esquema de direitos e obrigações que sinalize ao mercado fortemente quais medidas são legais, quais são ilegais (o que cria incentivos positivos e negativos muito fortes aos entes privados que negociam), de modo a dar segurança de que obrigações assumidas poderão ser cumpridas (o que é essencial para a internacionalização das cadeias de produção, das relações comerciais e dos fluxos de capital). Idealmente falando, os cidadãos dos países levam seus governos a assinarem tais tratados (que impingem fortes restrições em seus poderes de definir soberanamente suas políticas públicas) porque acreditam estarem ganhando, com isso, a possibilidade de participar de um ambiente econômico internacional mais propenso ao investimento do qual aproveitariam. ${ }^{39}$

A preocupação de uma Constituição Econômica Internacional refere-se, portanto, à criação de regras que permitam que os países descubram suas preferências, engajando-se num debate público sobre quais medidas são importantes para o aumento de seu bem-estar.

11. Integração econômica, instituições e desenvolvimento: boas políticas, melhoria do bem-estar social e o diferencial dos países em desenvolvimento

A decisão de se integrar à economia mundial é, assim, contextualizada. Ela requer reformas nas instituições nacionais, de modo a adaptá-las ao regime multilateral às regras internacionais. Fstes custos de adaptação são fardos pesadíssimos a se carregar, já que requerem intensos investimentos estatais, ${ }^{40}$ ensejam altos custos de

38 Fazem parte desta idéia de field leverage o conjunto de medidas que dão corpo ao que se convencionou chamar de Principio da Nação Mais Favorecida (MFN - Most Favored Nation) e Principio do Tratamento Nacional (National Treatment). Destaco Jackson (2002) e Trebilcock e Howse (2002).

39 Vide nota 37. Complementando-a, pode-se dizer que, nesse sentido, há um certo nexo em se defender a positivação de instrumentos que garantam que os cidadãos exerçam plcno controle sobre seus govermos. Dai alguns autores, como Rodrik (2001) postularem que paises não-democráticos não deveriam poder contar com os mesmos privilégios de paises democráticos. Esta também é uma forte razão para ligar Acordos Comerciais com uma cláusula democrática. Vide o caso do Mercosul e as discussões sobrc democracia na ALCA

40 Vide, por exemplo, Wilson (2002). 
oportunidade," têm resultados incertos ${ }^{42}$ e podem mesmo levar a situações em que o bem-estar da comunidade se reduz. ${ }^{13}$

O timing, ritmo e os objetivos especificos que cada pais segue ao decidir absorver o esquema institucional que o habilita para participar do sistema multilateral de comércio apontam para um regime assimétrico de integração. Uma das provas mais cabais desta afirmação encontra-se na história institucional do GATT. Finger e Winters (2000: 385-390), por exemplo, realizaram um estudo sobre assunto. Notaram que as motivações e as formas pelas quais paises desenvolvidos e países em desenvolvimento ingressaram no projeto de uma ordem jurídica internacional das transações econômicas é diferenciado, pelo menos prima facie. Enquanto entre os países desenvolvidos o movimento de liberalização comercial, que se iniciou no pós-guerra, teve como caracteristica a reciprocidade, no caso dos nouveaux arrivants a época-chave são as décadas de 80 e 90 , acontecendo através de decisões unilaterais. Do mesmo modo, dispositivos de restrição à liberalização comercial do GAT" como salvaguardas, medidas compensatórias, proteção antidumping -, têm significados diferentes para cada uma das duas classes de países. Segundo os autores, no contexto de reciprocidade onde as concessões são mútuas e as negociações se alongam por anos - tais medidas têm uma finalidade de promover a continuidade do processo de liberalização. de modo a funcionarem como válvulas de escape para dissipar pressões protecionistas. Já no caso da integração por via unilateral. eles são vistos como guidelines de "boa política": são adotados como parte de um esquema institucional de modernização. Destarte. "boas políticas" são aquelas que podem ser previstas. os riscos são baixos e mais importante - são efetivas e de baixo custu. Fxiste, portanto. uma certa forma de desenhar os mecanismos de controle da atividade econômica de forma a obter resultados melhores ${ }^{4+}$

4 Vide Gilpin (2001: 48-49), por exemplo. O autor explica yue toda decisão tomada implica na perda de uma oportunidade de agir de outro modo - o que poderia levar a beneficios de outra ordem. "There is no such thing as free lunch (TSTFL)», resume.

42 Vide Dixil (1999). Sengundo o autor, reformas institucionais devem ser feitas através de um desenho de mecanismos de mudança que levern em conta a possibilidade de defeitos de informação e açōes não previsiveis.

43 O caso da Argentina ċ um exemplo clássico.

4 Limitaçòes nas "quatro liberdades económicas» - liberdade de movimento de (i) mercadorias, (ii) scrviçus. (iii) capital e (iv) pessoas - são comuns em diversos paises no mundo, independente de seu nivel relativo de desenvolvimento. No entanto, do ponto de vista da transparência das politicas públicas e instrumentos de intervenção. existem diversas formas de efetivá-las. Em grande parte dos paises desenvolvidos, a atividade privada - nacional ou internacional - é protegida contra a ingerència do poder público através de instituições que separam a esfera pública da privada enfaticamente. Assim, a ingerência pública na esfera privada de direitos se dá de forma expressamente prevista, justilicada e de forma a atingir objetivos claros, expressos e puiblicos no sentido jurídico de «interesse público» e no sentido corrente de "publicizado». O critério de aplicação das mediclas não é meramente politico (c. portanto, puramente discricionário e nào previsivel) mas sim jurisdicionalizado - vide a Cour of Imternational Tiade americana, responsável pela aplicação do direito antidumping nos EUA. Chama-se aqui de 
- assim, um critério objetivo através da qual a boa política pode ser aferida é viável. Chama-se esse critério de critério da intervenção fundamentuda. Países que buscam o desenvolvimento através da inserção na economia mundial incorporam instituições estrangeiras justamente para tornar seu ambiente econômico mais "investment friendly"

Schaffer, Earle e Agusti, em seu Manual de Direito das transações econômicas internacionais, dedicam uma seção especial de seu capitulo introdutório ao "ambiente legal dos negócios internacionais" (2002: 5-4l). Eles associam os controles ineficientes ${ }^{45}$ sobre a atividade econômica impostos pelos países em desenvolvimento a riscos que devem ser considerados quando se faz negócios. São de quatro ordens as preocupações principais dos investidores internacionais: (a) preservação do valor dos ativos tangiveis no estrangeiro, através de garantias relacionadas com a manutenção das taxas de câmbio, (b) preservação do valor dos ativos intangiveis, com garantias relacionadas com a propriedade intelectual, (c) preservação da organização industrial. com garantias relacionadas ao livre-comércio e (d) preservação do livre-fluxo de capitais, com garantias relativas ao investimento.

12. Instituições e o conceito de desenvolvimento: melhoria do bem-estar social via integração econômica internacional

E se regras de comércio internacional fossem interpretadas como regras para a melhoria das condições de vida ao invés apenas de regras para a redução de tarifas? ${ }^{46}$ Fsta passagem de uma perspectiva meramente liberalizante para uına

intervenção fundamentada a ação do Estado de forma a interferir na esfera de dircitos privados que implica em ganhos maiores do que scus custos. Como exemplo. estão as ações que reduzem custos de transação. suprem de informaçóes os agentes privados. aumentam os ganhos dos participantes das trocas comerciais (ou, pelo menos. permitem qui eles usufruam completamente dos benefícios de suas açóes). reduzem os riscos e aumentam as oportunidades de negócio. valorizando ativos. Vide World Bank (2001: 3). Ressaltase que fundamentada vem aqui como referência ao tcrmo em inglês reasonable.

t5 Vide nota anterior. Como exemplos de controles que são comuns em diversos paises no mundo. mas nos paises em desenvolvimento assumem a faceta de alıo risco à atividade econômica no plano internacional devido à deficiências institucionais relacionadas com os ordenamentos juridicos nacionais, politicas públicas ineficientes ou mal-concebidas. imprevisibilidade em razão da falta de regras claras, arbitrariedade de julgamentos e falta de isonomia estão: (a) controles cambiais; (b) controles comerciais relativos a políticas protecionistas que envolvem restrições às trocas de mercadorias e serviços e flexibilização dos direitos de licenciamento de nuarcas e patentes, (c) controles de investimentos, com nacionalização forçada de empresas e limites na repatriação de lucros. Vide Schaffer, Earle e Agusti (2002: 20-21).

t6 O texto que inspira este questionamento é Rodrik (2001). Nele, o autor desenvolve, através do viés da economia politica, uma análise programática do que deveria ser o sistema de regulaçào do comércio internacional se fosse adotada năo mais uma visão meramente liberalizante, mas uma visào desenvolvimentista. No entanto, noto ayui pelo menos uma diferença na perspectiva deste texto $\mathrm{cm}$ relação àquela assumida por Rodrik: não ofereço um programa de ação. com principios e estratégias a serem adotadas nas negociaçòes comerciais que se seguirão, mas sim. uma interpretação das regras atuais tomando como base o conceito advindo da análise econômica do direito de melhoria das condiçōes de vida. 
perspectiva de bem-estar social, na qual a regulação do comércio internacional por meio do Direito das Transações Econômicas Internacionais só tem sentido se apontar para uma melhoria das condições de vida da comunidade internacional.

Sendo assim. a política comercial. mais do que uma política de integração econômica via abaixamento de tarifas, deve ser vista como uma política de integração econômica via reforma institucional. ${ }^{\text {4` }}$ Rodrik (2002: 3) é enfático em afirmar que este tipo de reforma vai bem mais longe do que o compromisso com níveis de tarifas e restrições quantitativas: envolve o estabelecimento de normas e expectativas de como políticas públicas serão implementadas. estabelecimento de incentivos positivos e negativos a agentes privados, restrições e oportunidades que dão origem a novas formas de comunidades se organizarem.

Dai que os compromissos assumidos pelos países tendo em vista a implementação de regras de comércio internacional não podem ser vistos como meros compromissos tarifários, mas sim compromissos de reforma de instituições nacionais e criação de instituições que suportem a integração econômica internacional. Governos nacionais assumem compromissos, concretizados em direitos e deveres, de promover mudanças em suas instituições, de modo a possibilitar a melhoria do bem-estar de suas populações através da integração econômica. Em outras palavras, eles decidem participar de uma economia cujas instituições são desenhadas de modo consistente. de forma a promover o dinamismo empresarial e o crescimento econômico. Esta participação relaciona-se, portanto. com a criação de um ambiente institucional de alta qualidade no plano interno - tal é o critério pelo qual. segundo a hipótese deste trabalho. devem ser as políticas públicas dos governos nacionais julgadas pelo tribunal que é a Organização Mundial do Comércio.

\section{Conclusão}

O objetivo deste texto era verificar a possibilidade de se utilizar, como certos doutrinadores atuais fazem, a possibilidade de se aplicar o conceito de constituição às regras concernentes à regulação das atividades econômica internacional. Para isso, fez-se uma reconstrução institucional e intelectual do Direito do Comércio Internacional, reproduziu-se as principais doutrinas envolvendo o debate constitucionalista na atualidade criticando-se a utilização da linguagem

Rodrik (2002) explica esta diferença como sendo uma diferença de visùes de mundo: enquanto os economistas vêem a politica comercial como uma questão de modelagem matemática, na qual o resultado mais eficiente da alocação de recursos poderá ser medido. os idealizadores de politicas públicas (policymakers) a vèem como parte de um processo de transformaçào das instituiçòes públicas de modo a modificar o comportamento tanto dos agentes públicos quanto privados. 
constitucionalista com base nos fundamentos libertários, integracionistas e jurídicosistêmicos - para, por fim, propor uma formulação mais neutra de Constituição Econômica Internacional e que fosse sensivel à questão da legitimidade. Esta interpretação consideraria que estariam criadas as condições para a cooperação entre as nações, num mundo em que as economias nacionais se integram velozmente. Constituição Econômica Internacional teria a ver, portanto, com o estabelecimento de condições propícias para que as deliberações sobre o manejo desta integração pudessem acontecer. Em outras palavras, com regras básicas fundem a Comunidade Econômica Internacional. O critério essencial para identificação da presença da estrutura constitucional é justamente o requisito de que a tomada de decisões seja feita com base na consideração e respeito das opiniões e interesses daqueles que participam da Comunidade.

São Paulo, dezembro de 2006.

\section{Referências}

ABBOTT, K. W. Keohane, R. O., Moravcsik, A., Slaughter, A.M. ¿ Snidal, D. (2000), The Concept of Legalization, 54 Int'l Org. 401.

ADDA. J. (1999). La Mondialisation de l'économie, 2 Volumes, Paris : La Découverte.

ALSTON, P. (2002), Resisting the Merger and Acquisition of Human Rights by Trade Law: A Reply to Petersmann, 13 Eur: J. of Int'l L. 4 .

AUBIN, C. (2000), Stratégies des Firmes et Échanges Internationaux, in Yves Léonard (dir.) (2000), Les Cahiers Français Le Commerce Mondial, Paris : La Documentation Française.

AXFLROD, R. M. (1980), The Evolution of Cooperation. New York: Basic Books.

BALDWIN, R. E. (1993), Adapting the GATT to a More Regionalized World: A Political Economic Perspective, in Kym Anderson e Richard Blackhurst (ed.), Regional Integration and the World Trading System, New York: St.Martin's Press.

BALDWIN, R. E. (2000), Imposing Multilateral Discipline on Administered Protection, in Annc O. Krueger (ed.), The WTO as an International Organization, Chicago: Chicago University Press.

BENVENISTI, E. (1999), Exit and Voice in the Age of Globalization, 98(1) Vich. L. Rev: 167.

BHAGWATI, J. (1988), Protectionism, Cambridge: (ambridge Univesity Press. 
BLACKHURST, R. (2000), The Capacity of the WTO to Fulfill its Mandate, in Anne O. Krueger (ed.), The WTO as an International Organization, Chicago: Chicago University Press.

BORDU, M. D., Taylor. A. M. e Williamson, J. G. ed. (forthcoming). Globalization in Historical Perspective, Conference held in May 4-5. 2001, ('hicago: Chicago I Iniversity Press. Disponivel no site http://www.nber.org/books/global/index.html.

BRATHWAITE, I. e Drahos, P. (2000). International Business Regulation, Cambridge: Cambridge University Press.

BRONCKERS (1999), M. Bettcr Rules for a New Millenium: A Warning Against I'ndemocratic Developments in the WTO 2(4) J. of Int'l Econ. L..

BUChANAN. J. (1977). Freedom in Constitutional Contract Perspectuves of a Political Economist, College Station and I.ondon: Texas A\&M University Press.

BUCHANAN. J. (1991), The Economics and the Ethics of Constitutional Order, Ann Arbor: Michigan l!niversity Press.

BUCHANAN. J. e 'lullock. G. (1962), The Calculus of Consent, Ann Arbor: Michigan University Press.

CAMERON, R. e Neal. L. (2003), A Concise Economic History of the World: From Paleolithic Times to the Present, Oxford: Oxford University Press.

CAPUL, J. Y. (1999), Dictionnaire d'économic et de sciences sociales, Paris : Hatier.

CARR, E. H. (1951), The Twenty Years Crisis 1919-1939: An Introduction to the Study of International Relations. London: McMillan

CASS, D. Z. (2001). The 'Constitutionalization' of the Intemational Trade Law: Judicial NormGeneration as the Engine of the Constititional Development in International Trade, 12 Eur: J. of In'l Law; l.

CAVES, R. E. (1982). Multinational Enterprises and Fconomic Analysis, Cambridge: Harvard University Press.

CORDEN, W. M. (1984), The Revival of Protectionism, New York: Group of Thirty.

CUTTIER, T. (2000), Limits to International Trade: The Constitutional Challenge. Washington: paper apresentado na American Society of International Law.

COX, R. (1987), Production, Power and World Order: Social Forces in the Making of History. New York: Columbia University Press. 
CHARNOVITZ, S. (2001), The WTO and the Rights of the Individual, Intereconomics, March/April.

CHO, S. (1999), GATT Non-Violation Issues in the WTO Framework: Are They the Achilles' Heel of the Dispute Settlement Process?, 39 Harvard Int'l L. J. 2.

DAVII:S, J. P. (1961), Corporations: A Study of the Origin and Development of Great Business Combinations and their Relation to the Authority of the State, Nuw York: Capricon Books.

DIXIT, A. (1999) Some lessons from transaction-cost politics for less-developed countries, paper presented to the Latin America meeting of the Econometric Society, Cacun, México, August.

DOREMUS, P. N., Keller, W.W., Pauly. L.W. e Reich. Simon (1998), The Myth of the (jlubal Corporation, Princeton: Princeton University Press.

DUNNING, J. N. (1981), International Production and the Multinational Enterprise. London: Allen and Unwin.

DLNNING, J. N. (1988), Explaining International Production, London: Unwin Hyman.

DUNOFF, J. (1999), The Death of the Trade Regime, I0 Eur. J. of Int'l L. 733.

DWORKIN, R. (1997), Law's Empire, ('ambridge: Harvard University Press.

ELSTER, J. (2001), Ulysses Unbound, Cambridge: Cambridge University Press.

ETHIER, W. J. (1986), The Multinational Firm, Quartely Journal of Economics 101.

FERgusON, N. (2001), The Cash Vexus: Money and Power in the Modern World, 1700-2000, New York: Basic Books.

FINGER, M. e Winters, L.A. (2000). What can the WTO do for developing countries, in Anne O. Krueger (ed.), The WTO as an International Organization, Chicago : Chicago University Press.

FURMAN-PECK, J. (1983). A History of the World Economy, Ottawa: Barnes \& Noble.

FREY, B. (1984), International Political Economics, London: Basil Blackwell.

GARNER. B. A. (ed.) (2001). Black's Lun: Dictionary, St. Paul: West Group.

GATT (1986), Ministerial Declaration of the liruguay Round. MIN.DEC. de 20 du setembro du 1986, Genebra: GATT.

GILPIN, R. (2001) Global Political Economy: Understanding the Internacional Economic Order; Princeton: Princeton University Press. 
GOLDSTEN, J. (2000), International Institutions and Domestic Politics: GATT, WTO and Liberalization of International Trade, in Anne O. Krueger (ed.), The WTO as an Internutional Urganization, Chicago: Chicago University Press.

GOWA, J. (1989), Anarchy, Fgoism and Third Images: The Evolution of Cooperation in International Relations, 40 International Organization 1.

HART, H. L. A. (1994), The Concept of Law, Oxiord: Clarendon Press.

HIL.F, M. e Petersmann, E.U. (1993), National Constitutions and International Economic Law, The Hague: Kluwer Law International.

HINDLEY, B. e Messerlin, P. (1996), Antidumping Industrial Policy, Washington: AEI Press.

HIRSCHMANN, A. O. (1981), The Rise and Fall of Development Fconomics, in A. O. Hirschmann, Essays in Trespassing: Economics to Politics and Beyond. New York: Cambridge University Press.

HOEKMAN, B. e Kostecki. M. (2001), The Political Economy of the World Trade System: The WTO and Beyond, Oxford: Oxford University Press.

HOLMES, P. (2001), The WTO and the EU: Some Constitutional Comparisons, Lniversity of Sussex at Brighton Discussion Paper. Mimeo.

HOWSE, R. (1999). Tribute: The House that Jackson Built: Rustructuring the GATT System, 20 Mich. J. Int \% L. 107.

HOWSE, R. (2001), The Legitimacy of the World Trade Organization in J.-M. Coicaud e V. Heiskanen (eds.), The Legitimacy of International Organizations, Tokyo: The United Nations University Press.

HOWSE, R. (2002), Human Rights in the WTO: Whose Rights. What Humanity? Comment on Petersmann, 13 Eur: J. of $\operatorname{lnt}$ ' L. 3.

HOWSE, R. e Nicolaidis, K. (2003), Enhancing the WTO Legitimacy: Constitutionalization or Global Subsidiarity?, in Marco Verweij e Tim Josling (eds.), Deliberately Democratizing Multilateral Organization, special issue of Governance.

HOWSON. S. e Moggridge. D. (1990), The Collected Papers of J. James Meade, London: Unwin Hyman.

HUCK. H. M. (1994), Sentenca Estrangeira e Lex Mercaloria: Horizontes e Fronteiras do Comercio Internacional, São Paulo: Saraiva. 
HUDEC, R. E. (1990). The GATT System und the World Trade Diplomacy, St. Paul: Butterworth. HUDEC, R., Kennedy, P. e Sgarbossa, M. (1993), A Statistical Profile of GATT Dispute Settlement Cases, 1948-1989, 2 Minn. J. of Global Tr. 1.

IRWIN, D. A. (1998), Against the Tide: An Intellectual History of Free Trade. Princeton: Princeton University Press.

JACKSON, J. H. (1969). World Trade and the Law of GATT, Indianapolis: Bobbs-Merril.

JACKSON, J. H. (1980), The Birth of the GATT-MTN System: A Constitutional Appraisal, 12 L.\&Pol'y Bus. $2 I$.

JACKSON, J. H. (1990), Restructuring the GATT System, London: Royal Institute of International Affairs.

JACKSON, J. H. (1992), Status of Treaties in Domestic Legal Systems: A Policy Analysis, $86 \mathrm{~J}$. Int'l L. 310,311.

JACKSON, J. H. (1993), National Constitutions, Transnational Economic Policy and International Economic Law: Some Summary Reflections in M. Hilf c E. U. Petersmann, National Constitutions and International Economic Law, The Hague: Kluwer Law International.

JACKSON. J. H. (1995), Legal Problems of International Economic Relations: Cases, Texts and Materials. St. Paul; West Publishing Co.

JACKSON, J. H. (1998), Global Economics and International Economic Law, I J. of Int'l Econ. L. I.

JACKSON, J. H. (1998b), The World Trade Organization: Constitution and Jurisprudence,

JACKSON, J. H. (2000), The Perils of Globalization and the World Trading System, 24 Fordham Int'l L. J. 371 .

JACKSON, J. H. (2002), World Trading System: Law and Policy of International Economic Relations, Boston: Massachusetts Institute of Technology Press.

JULIUS, D. (1990), Global Compunies und Public Policy: The Growing Challenge of Fureign Direct Investment, London: Pinter.

KELSEN, H. (1998), Teoria Geral do Direito e do Estado, São Paulo: Martins Fontes.

KENNEDY. D. (1994), The International Style in Postwar Law and Policy. 1994 (Itah L. Rev. 7. KENNEN, P. B. (2000), The International Economy. Cambridge: Cambridge University Press. 
KEOHANE, R. O. (1984), After Hegemony: Cooperation and Discord in World Political Economy, Princeton: Princeton University Press.

KINDLFBERGER, C. (1975), The Rise of Free Trade in Western Europe, 1820-1874, J. Of Econ. Hist. 20).

KRAAY, A. e Dollar, D. (2001), Trade, Growth and Poverty, Washington: Development Research (iroup, World Bank.

KRAJEWSKI, M. (2001), "Democratic Legitimacy and Constitutional Perspectives of WTO Law", 31 J. of World Trade 1.

KRASNER, S. D. (ed.) (1983), International Regimes, Jthaca: Comell University Press.

KRUEGER. A. O. (1995), American Trade Policy: A Tragedy in the Making, Washington: AFI Press.

KRUGMAN, P. (1996), Pop Internationalism. (ambridge : MIT University Press, trad. ing. de Anne Saint-Girons (2000), "La Mondialisation n'est pas Coupable : Vertus et L.imites du LibreÉchange", Paris : La Découverte.

KRUGMAN. P. e Obstfeld. M. (2000), International Economics: Theory and Policy, New York: Addison-Wesley Longman.

LAFER, C. (1996), O Sistema de Soluçuo de Controvérsias da Organizaçao Mundial do Comércio, Documentos, Debates, Estudos. Instituto Roberto Simonsen, n. 3.

LEVY, M. A., Young, O. R. e Zürn. M.. The Study of International Regimes, I Eur: J. of Int'l Relations 267.

MADISON, J. (1952). Number 10. in Alexander Hamilton, James Madison e John Jay. The Federalist, Chicago: Fencyclopedia Briannica. Inc.

MARKUSEN, J. R. (2002): Multinational Firms and the Theory of linternational Trade. Cambridge: The MIT Press.

MATALONI, R. J. e Yorgason, D. R. (2002), Operation of U.S. Multinationals Companies: Preliminary Results from the 1999 Benchmark Survey. in Bureau of Economic Analysis, Surve of Current Business March 2002. Washington: U.S. Department of Commerce.

MCGINNINS. J. O. e Morsesian, Mark K. (2000). The World Trade Constitution. II4 Har v: I.. Rev. 511 .

MESSERLIN, P. (1999), Commerce International, Paris : Daloz. 
MILNER, H. (1997), Interests, Institutions and Information: Domestic Politics and International Relations, Princeton: Princeton University Press.

MUEller, D. (1989), Public Choice II. Cambridge: Cambridge University Press.

MUNDEL.L, R. A. (1957), International Trade and Factor Mobility, American Economic Revies. 47.

NORTH, D. (1990). Institutions, institutional change and economic performance, Cambridge: Cambridge University Press.

ODELL, John e Eichengreen. Barry (2000). The United States, the ITO and the WTO: Exit Options. Agent Slack and Presidential Leadership. in Anne O. Krueger (ed.). The WTO as an International Organization, Chicago: University of Chicago Press.

OHMAE, K. (1990), The Borderless World: Power and Strategy in the Interlinked Economy; New York: HarperBusiness.

OLSON, M. (1965), The Logic of Collective Action: Public Goods and Theory of Groups, Chicago: Chicago University Press.

OSTRY, S. (1997), A New Regime for Foreign Direct Investment, Washington: Group of Thirty.

OYE, K. A. (ed.), (1986), Cooperation under Anarchy, Princeton: Princeton University Press.

PALMETER, D. (2000), The WTO as a Legal System, 24 Fordham Int'l I. J. 444.

PETERSMANN, E.U. (1991), Constitutional Functions and Constitutional Problems of International Economic Law, Fribourg: University Press.

PETERSMANN. E.U. (1998), How to Constitutionalize International Law and Foreign Policy for

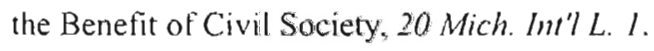

PETERSMANN, E.U. (2000), WTO Constitution and Human Rights, 3 J. of Int'l Ec. L. I.

PETERSMANN. E.U. (2002), Time for a Linited Nations 'Global Compact' for Integrating Human Rights into the Law of Worldwide Organizations: Lessons from European Integration, 13 Eur. J. of In'l L. 3 .

PETERSMANN, E.U. (2002b), Taking Human Dignity, Poverty and Fmpowerment of Individuals More Sereously: Rejoinder to Alston, 13 Eur: J. of In''l L. 4.

PURTER, M. E. (1990). The Competitive Advantage of the Nations, New York: Free Press.

PRZEWORSKI. A. (1990), The State and the Economy Under Capitalism, Chur. Switzerland: Harwood Academics Publishers, 1990. 
RAWLS. J. (1972), A Theory of Justice, London: Oxford University Press.

RAWLS, J. (2001), Direito dos Povos, São Paulo: Martins Fontes.

RODRIK, D. (2001), The Global Governance of Trade as if Development Really Mattered, New York: United Nations Development Programme.

RUDRIK, D. (2002), Trade Policy Reform as Institutional Reform, in B. Hoekman, A. Mattoo, ¿ P. English (eds), Developinent. Trade, and the WTO: a Handbook. Washington: the World Bank.

ROSSLER, F. (2000), Domestic Policy Objectives and the Multilateral Trade Order: Lessons from the Past, in Anne O. Krueger (ed.), The WTO as an International Organization. Chicago: Chicago University Press.

RUGGIE, J. (i. (1983), International Regimes, Transactions and Change - Embedded Liberalism in the Postwar Economic Order, in Stephen D. Krasner (ed.) International Regimes, Ithaca: Cornell University Press.

SCHAFFER, R.. Earle, B. e Agusti, F. (2002). International Business Lau and its Environment. Ohio; West Legal Studies in Business.

SCHNEIDER. A. K. (1998). Individual Rights in International Trade Organizations, 19 L!. Pa. J. Int'l Econ. L. 587.

SCHULTZ, T. W. (1964), Transforming the Traditional Agriculture, New Haven: Yale University Press.

SEN. A. K. (2000), Development as Freedom, New York: Anchor Books.

SHELL, G. R. (1995), Trade Legalism and International Relations Thory: An Analysis of the World Trade Organization, Duke' L. J. 829.

SIMMA, B. (1995), "The Contribution of Alfred Verdross to the Theory of International Law", 6 Europ. J. of Int'l L..

SI.AUGHTER, A.-M. (1998), Regulation the World: Multilateralism, Internationalism and the Projection of the New Deal Rugulatory State, in Robert Howse (ed.), The World Trading System: Criticul Perspectives on the World Economy, New York: Routledge.

SOMFK. A. (2001), On Supranationality, 3 Florida Coast. L. J. 23.

STEGER, D. P. e Hainsworth, S.M. (1999). New Directions in International Trade Law: WTO Dispute Settlement in J. Cameron e K. Campbell (eds.), Dispute Resolution in the World Trade' Organization. London: Camaron May. 
STEHMANN, O. (1999), Export Subsidies in the Regional Aircraft Sector The Impact of the Two WTO Panel Rulings against Canada and Brazil, $33 \mathrm{~J}$. of World Trade 6.

STEPHAN, P.B. (2002), Institutions and Elites: Property, Contract, the State and Rights in Information in the Gilobal Economy, 10 Cardozo J. of Int'l \& Comp. L. 305.

SUNSTEIN, C. (1991), On Property and Constitutionalism, John M. Olin Program in Law \& Economics Working Paper n. 03/91, Chicago: University of Chicago Law School.

SUNSTEIN, C. (2001), Designing Democracy: What ('onstitutions Do, ()x ford: Oxford University Press.

SWEFT, A. S. (1999), Judicialization and the Construction of Governance, 32 Comp. Pol. Studies 149.

TRI:BILCOCK, M. J. e Howse, R. (2002). The Regulation of International Trude, London: Routledge.

TRUYOL Y SERRA, A. (1995), Verdross et la Théorie du Droit, 6 Furop. J. of Int'l L..

UIA - Union of International Association, Yearbook of International Organizations, Munich: K.D. Sauer.

UNCTAD (2000), World Investment Report, New York: United Nations.

UNCTAD (2002), World Investment Report. New York: United Nations.

VAN THEMAAT. P.V.L. (1987), Restructuring the International Economic Order, in P. van Dijk, F. van Hoof, A. Koers e K. Mortelmans (eds), Restructuring the International Economic Order: The Role of Law and Lawyers, Daventer: Kluwer.

VERDROSS, A. (1950), Völkrrecht, Berlin: Springer, trad. de Antonio Truyol y Serra, Derecho Internacional Publico (1974), Madrid: Aguilar.

VERDROSS, A. e Simma, B. (1984), Universelles Völkerrecht. Berlin: De Gruyter.

VERNON, R. (1971), Sovereignty at Bay, New York: Basic Books.

VOIGT (2000), Constitutional Law, in B. Bouckaert, e G. De Geest (eds.), Encyclopedia of Law and Economics, Cheltenham: Edward Elgar.

WATSON, A. (1991), The Evolution of the International Society, London: Routledge.

WATSON, J. (2002), Strategy: An Introduction to Game Theory, New York: W. W. Norton \& Company. 
WEILER, J.H.H. (1991). The Transformation of Europe 100 The Yale L. J. 2403.

WEILER, J.H.H. (1995), Does Europe Need a Constitution? Demos, Telos and the German Maastricht Decision:, 3 Eur. L. J. 219.

WEILER, J.H.H. (1999), The Constitution of Europe: Do the New Clothes Havc an Fimperor? And Other Essays on European Integration, Cambridge: Cambridge University Press.

WEILER, J.H.H. (2000). Federalism and Constitutionalism: Europe's Sonderweg, Jean Monnet Working Paper n. 10/00.

WILSON, J. S. (2002), Standards, Regulation and Trade: WTO Rules and Developing Countries Concerns in B. Hockman, A. Mattoo, \& P. English (eds), Development. Trade, and the WTU: a Handbook, Washington: The World Bank.

WTO (1994), Agreement Estahlishing the World Trade Organization, Marrakesh: World Trade Organization.

YERGIN, D. ¿ Stanislaw, J. (1999), The Commanding Heights: The Battle Berween Government and the Marketplace that is Remaking the Modern World, New York: Simon \& Schulstur.

ZLEPTNI(i. S. (2002). The Standard Review in WTO Law: An Analysis of Law. Legitimacy and the Distribution of Legal and Political Authority, 6 Eur. Int. Online p. 17. 